УДК 372. 881.

\title{
РОЛЬ ДИАЛОГИЧЕСКИХ ВЫСКАЗЫВАНИЙ В ОРГАНИЗАЦИИ РЕЧЕВОЙ КОММУНИКАЦИИ
}

\author{
T.Т. Абдукадырова \\ кандидат педагогических наук, доцент кафедры немецкого языка \\ Т.Р. Яскиева \\ магистрант 1-го курса факультета иностранных языков \\ «Чеченский государственный университет»
}

\begin{abstract}
Аннотация: Предлагаемая статья рассматривает одну из актуальных проблем как организация диалогических высказываний в речевой коммуникации. В качестве одной из доминирующих интенций диалогических высказываний выступает побуждение. Важность данной статьи обусловлена тем, что делается акцент на изучении диалогических речевых образований, которые представляют собой последовательность высказываний с некоторыми актуализированными интенциональными потенциалами, совокупность которых образует структуру диалога.
\end{abstract}

Ключевые слова: диалог, коммуникация, интенция, побудительная интонация, иллокутивный характер, вербальные и невербальные средства.

\section{THE ROLE OF DIALOGIC STATEMENTS IN THE ORGANIZATION OF SPEECH COMMUNICATION}

\section{T.T. Abdukadyrova T.R. Yaskieva}

\begin{abstract}
The proposed article considers one of the actual problems as the organization of dialogic statements in speech communication. One of the dominant intentions of dialogic utterances is the urge. The importance of this article is due to the fact that the emphasis is placed on the study of dialogic speech formations, which are a sequence of statements with some actualized intentional potentials, the totality of which forms the structure of the dialogue.
\end{abstract}

Key words: dialogue, communication, intention, motivational intonation, illocutionary character, verbal and nonverbal means. 
В последние годы в лингвистике возрос интерес исследователей к изучению диалогической речи. Причина этого кроется в том, что именно в диалоге наиболее органично выражена коммуникативная функция языка, естественно проявляющаяся в процессе языкового взаимодействия людей [1, c.19].

По мнению Л.В. Шевелевой, диалог создается под влиянием различных факторов, подразумевающих как отношение к партнеру по коммуникации, так и соблюдение определенных норм, условностей речевого поведения и эмоционального состояния коммуникантов [4, с.59]. Следует отметить, что характерной чертой диалога является обязательная смена коммуникативных ролей.

Автор инициативной реплики занимает более активную позицию в коммуникативном акте: он определяет тему последующего высказывания и определяет дальнейшее развитие диалога. Другой речевой партнер в своих ответных репликах обычно только следует заданной теме.

Все это указывает на возможность различения определенного расширенного диалогического высказывания, a также внутренне объединенного с наличием определенного намерения. В этом случае вербальная организация данного высказывания может быть очень разнообразной, состоящей из нескольких предложений» [4, с.59].

В качестве одной из таких доминирующих интенций диалогических высказываний выступает побуждение. Диалогическое высказывание с побудительной интонацией в соответствии со своей авторской принадлежностью представляет собой обычно инициативную реплику, которая может состоять из одного или более предложений.

С точки зрения В.В. Богданова в диалогических высказываниях с побудительной интенцией, эксплицитно выраженной одним иллокутивно однозначным предложением, используются только те языковые средства, которые непосредственно специализируются на выражении данного значения $[1$, c.56].

Далее следует отметить, что подобные высказывания характерны только для таких коммуникативных ситуаций, где взаимодействия партнёров строятся либо на отношениях с неравными социальными статусами, либо на отношениях равноправия: Komm! Gehen wir! Er gehe! Aufstehen! Stillgestanden! Feuer! Vorwärts! u m.d.

Большей частью собственно побудительные предложения с интонацией сообщения, представляющие собой наиболее «слабый» компонент 
классической трехчленной оппозиции предложений по цели высказывания, могут выполнять в речевых образованиях самые разнообразные функции, которые способствуют более полному раскрытию установки говорящего [1, c.20]. Так, в случае построения межличностных отношений между коммуникантами по принципу «снизу-вверх» или на равноправных началах для реплики коммуниканта, от которого исходит побуждение, характерно наряду с иллокутивно побудительной репликой наличие предложений, содержащих дополнительную информацию аргументирующего и пояснительного типа.

Данная тенденция к обрастанию побудительной реплики способствует наращиванию смысла диалогических высказываний, раскрывает механизм кооперации партнеров по акту коммуникации и позволяет соблюсти этикетные нормы речевого поведения. Так, например,

Gib dir Mühe, Kind, du weißt, wie schwer es mir wird, dich zur Schule zu schicken - und die Stunden kosten Geld [7, c.17].

Здесь для придания убедительности адресованного партнеру используются предложения с аргументирующей и причинно - следственной функцией.

Доминирующая интенция-побуждения может также выражаться рядом собственно побудительных предложений.

В следующем примере три мотивационных предложения сопровождают диалогическое утверждение, в то время как другие предложения, служат для поддержания данного намерения:

Mac! Mac, erschrick nicht. Ich bin bei Brown gewesen, und mein Vater ist auch dort gewesen, und sie haben ausgemacht, dass sie dich fassen wollen, mein Vater hat mit etwas Furchtbarem gedroht, und Brown hat zu dir gehalten, aber dann ist er zusammengebrochen, und jetzt meint er auch, du solltest schleunigst für einige Zeit unsichtbar werden, Mac. Du musst gleich packen [7, c.79).

Иногда диалогическое высказывание, состоящее из цепочки предложений, в том числе и побудительного, но оно не имеет общую побудительную направленность:

Komm, Jim, gehen wir. Die Zeitverschwendung, sich mit dieser Dame zu unterhalten. Sie will auf guten Rat nicht hören. Nach Allem, was passiert ist, wird sie sich hier sicherlich nicht mehr wohl fühlen. Die Leute starren sie an und tuscheln über sie [8,c.59]. В данном случае, основная цель говорящего не в призыве своего партнёра к совершению некоторого действия, а в попытке 
убедить третье участвующее в этом коммуникативном акте лицо посредством столь своеобразного аргумента в целесообразности осуществления желаемого для говорящего действия - продаже ему участка земли.

Значительно реже диалогическое высказывание вбирает в себя несколько иллокутивно тождественных предложений: Setzen Sie doch, Gelia, setzen Sie sich [8,c.27].

Повторение на коммуникативном уровне, усиливается лексическими и синтаксическими средствами, что весьма повышает степень эффективного воздействия на речевых партнеров.

Степень прагматической эффективности, а это именно то, что определяет выбор определенной словесной формы выражения стимулирующего намерения. Говорящий предпочитает использовать такие языковые средства, которые выражены более коммуникативно. Здесь уместно обратить внимание на то, что в диалогических высказываниях в качестве мотивационных реплик, часто используются транспонированные и коммуникативные типы предложений. Подобные реплики характеризуют весьма высокую степень речевого этикета:

Könnten Sie mit der Maschine hierbleiben und mir zu Hilfe kommen, wenn ich in Schwierigkeiten geraten sollte [8, c.137].

К данному положению следует добавить, что ответная реакция коммуниканта может иметь экстралингвистический или лингвистический характер. Однако, анализ несогласия адресата с интенцией говорящего может быть выражено как вербально так и невербально [1, с.20].

Коммуникативная значимость несогласия проявляется в том, что оно ведёт к изменению плана диалогического образования и может служить фактором для более крупных речевых образований на более мелкие.

Несогласие также может быть выражено любыми кинетическими средствами (например, покачиванием головой), что означает коммуникативно - осознанное для партнера замалчивание, которое представлено в диалоге как акт нулевого значения или попытка изменить предмет разговора: Bitte sagen Sie mir Ihren Namen und Ihre Telefonnummer. - Ach wie blöd, ich vereise morgen. Ich rufe Sie nächste Woche an, wenn ich wieder da bin [8,c.139].

Также весьма многообразно представлены в исследовании и вербальные средства выражения несогласия и обусловлены они примерно теми же причинами.

Несогласие с мотивационным намерением, которое вербально представляет собой лишь иллокутивную однозначную реплику, возможную 
только в условиях такого коммуникативного акта, участники которого социально равны и близко знакомы друг с другом. При этом следует заметить, что использование в данной ситуации предложения, объясняющего несогласие в прямой форме, очень маловероятно: "Mach das Fenster zu!" "Ich tue das nicht. Nein" [8,c.19].

Более узуально появление в аналогичном констекте реагирующей реплики, которая знаменует переход инициативы от одного речевого партнера к другому: "Mach das Fenster zu!’”-“Tue das selber!”.

Таким образом, в результате предварительных наблюдений можно сделать вывод о том, что диалогические речевые образования представляют собой последовательность высказываний с некоторыми актуализированными интенциональными потенциалами, совокупность которых образует интенциональную структуру диалога.

\section{Список литературы}

1. Богданов. В.В. Функции вербальных и невербальных компонентов в речевом общении, Калинин,1997. С.18 - 25.

2. Пеньков Е.М. Некоторые вопросы методологии...- М.: Мысль, 1982. $-198 \mathrm{c}$.

3. Плахов. В.Д. Социальные нормы. - М.,1985. - С.112 - 117.

4. Шевелева Л.В. Лексикология современного немецкого языка: курс лекций / Л.В. Шевелева. М.: Высшая школа, 2004. 240 с.

5. Gabriel G. Was sind Behauptungen? // Der Deutschunterricht. 1996, S.5-11.

6. Brecht B. Stücke. Berlin; Weimar, 1983.

7. Böll H. Und sagte kein einziges Wort. Köln; Berlin, 1984,192S.

8. Sherwood J. Kunst kann tödlich sein. Bern; München, 1984. 